\title{
On Overcoming Transitional Challenges of First Year Students in Technology-Based Educational Settings
}

\author{
Munienge Mbodila ${ }^{1}$, Isong Bassey $^{2}$, Muhandji Kikunga ${ }^{3}$ \\ ${ }^{1,3}$ University of Venda, Computer Science \& Info. Systems Department, Thohoyandou, South Africa \\ ${ }^{2}$ North-West University, Computer Sciences Department, Mafikeng, South Africa \\ Emai: \{munienge.mbodila, muhandji.kikunga\}@univen.ac.za, bassey.isong@nwu.ac.za \\ Langutani Masehele ${ }^{4}$ \\ ${ }^{4}$ University of Venda, CHETL, Thohoyandou, South Africa \\ Emai: mary.masehele@univen.ac.za
}

\begin{abstract}
Universities in South Africa (SA) are facing several challenges due to the influx of students with diverse backgrounds entering the first year. One of such challenges is the use of technologies for teaching and learning. Institutions in the rural areas are flooded with first year students characterized as under-prepared, educationally underprivileged and had little or no access to computer usage prior to their enrolment. These qualities impedes their transition into the computer-based learning system and other technologies that supports teaching and learning. Moreover, the students are not given the needed assistance when enrolled. Orientation programme that would have been a leverage is only informative and not supportive in nature. Thus, an effective solution requires orientation programme to be supportive. It should involve assessing students' profile during their first year registration to provide them with the needed assistance in terms of technologies usage. This paper conducted a pilot survey over a sample of first year entering students in the University of Venda (UNIVEN). The objective was to assess students in terms of technology-related uses, expectations, experiences, skill levels and training needs. Data collected were analyzed and the results show students' have not used computers or had experience on technologies for teaching and learning in their previous schools. Additionally, students are only technologically identified with their mobile phones. The study proposed a new programme called First Experience Computer Literacy (FECOL) to facilitate students' transition into the computer-based learning of the university.
\end{abstract}

Index Terms-First Year, Students, Technology, Computer, Module, University

\section{INTRODUCTION}

In recent years, South African (SA) universities have been faced with large influx of students entering higher institutions of learning. A considerable number of these students are from the poor communities in the rural areas and former black settlements which are still educationally disadvantaged embedded with under-preparedness. Consequently, this has created a negative impact on their transition into the universities as it involve a complex process that requires new skills acquisition, new academic and social environmental adjustment. Recent researches have shown that significant number of students in the institutions of higher learning experience at least some difficulties during their period of transition, but request a multi-dimensional reaction from each individual facing divergent changes. [1][2] stressed that the process could be experienced differently for each individual undertaking while [3] argues that the manner in which students integrate into the university life is directly related to both their performance at high school and their own socio-economic background.

In the perspective of teaching and learning technology usage, majority of the students have been tagged 'digital strangers' [4]. These students have very little access or had never used computers for teaching and learning prior to their university education. However, with the rapid advancement in information and communication technologies (ICTs) and its valuable impact on teaching and learning in Higher Education (HE), these 'digital strangers' face serious problems transiting into the computer-based technologies of the system. According to [4], though the students had used technologies like mobile phones, computers, digital music players, video games and cams, and so on their entire lives, the way they think, learn, communicate and connect is controlled by the digital culture and environment they resides. The claim however did not address their experience and training needs in the perspective of teaching and learning. Therefore, it is important to consider the background, the cultural and environmental assumptions underpinning the construct of the 'Digital Natives'.

Given the critical context and importance of technologies as core elements of educational development in $\mathrm{HE}$, it is of the essence that first year entering students are assessed on the technology-related 
uses and background. This is important to facilitate their successful transition from high school to the university mainstream which is today a computer-based learning setting. Moreover, it will assist them to cope with the use of technology for academic purposes and get integrated into the discourse of the university. To this end, approaches which offers flexible system of support should be adopted for the first year experience (FYE). In the SA HE context, the essence is that the increasing diversity of the students' population has change dramatically including different learner sets given their previous educational know-how and the level of underpreparedness.

Therefore, this paper performed a survey on first year students entering the University of Venda (UNIVEN) to assess each student's capabilities in technology-related uses, expectations, experiences, skill levels and training needs. The objective was to identify what forms of technology-related supports are needed by the students in order to cope with teaching and learning in their new academic environment. We collected data by assessing their profile, analyzed and presented. The results shows the first entering students' have not used computers or had experiences or skills on technologies for teaching and learning in their previous schools. As an early intervention, this study proposed a new programme called First Experience Computer Literacy (FECOL) in that regard.

The rest of the paper is organized as follows: Section II discuss the study background information, Section III presents the activity model during first few days in the university, Section IV is the access and technology usage of first year students and Section V is the analysis and results. Moreover, Section VI is study discussion, Section VII discusses the proposed FECOL module while Section VIII is the conclusion.

\section{RELATED WORKS}

In an attempt to create a smooth transition for the first entering students and to enhance teaching and learning activities, UNIVEN established a teaching and learning center which became operational in 2012 called the Academic Development Unit (ADU). During this period, the first institution wide student support programme was established. It operates in the form of a pilot peer mentoring programme for both first entering students and for 'at risk' students. By 'at risk' students, we meant students who are repeating one or more modules [5]. The concept was expanded to include students who are performing unsatisfactorily in the beginning stages of a module, either in their first formative assignments or class tests. The expansion was necessary because according to academic development practitioners, it will be hopeless to wait for damages to be caused instead of preventing them. Thus, to assist the 'at risk' students, the institution adopted the role-model theory, originally proposed by [6]. The adoption of the role model was to promote student-student interaction especially on the social level to create a feeling of belonging which [7] refers to as 'social fit'. In essence, it was to enable students to engage in a relationship that would eliminate fears but encourages free learning practices. To promote the initiative, third level students were recruited to participate in the programme in the capacity of peer mentors to assist the 'at risk' students to improve their performance. Nevertheless, the transition did not go well, especially for academics due to the extra burden and workload perceived. Academics believed it was needless having such programmes due to the existing structural challenges and lack of infrastructure.

In spite of the resistance, the programme took off and is gaining momentum today. Moreover, in 2015, the FYE concept was introduced via the teaching and learning centre and implemented by the student support sub-unit of the ADU. The programme included two hours contact sessions that would take place concurrently with normal lecture periods. The topics of discussion ranges from finance, health, student affairs, academic literacy skills to computer literacy skills. Facilitators were from various academic disciplines including administrative and support departments. Initially, there was enthusiasm but was calloff when they realized students were unresponsive to invitations. One of the reasons was that, students, especially in their first year of study are exposed to several activities that were somehow overwhelming to them. Consequently, they were not receiving the needed help and that affected their integration into the university system especially, in the use of technology for teaching and learning. This form the motivation for this paper. To save the situation and meet the dynamic needs of the diverse students' population, the thought of introducing a compulsory computer-based training and orientation for first entering students in UNIVEN emanated. Albeit it won't be an easy task since not all enrolled students have experienced computer usage. However, it is important for the ADU to support and be involved in the conceptualization of a computer-based compulsory module for all first year students in the institution.

\section{EARLy InSTITUTIONAL OPENING ACTIVITY MODEL}

Transition interventions are crucial for the success of students in the university due to influx of students' population with diverse backgrounds. Several studies in the literature have shown that first year students need help in order to adapt to campus life and also to enhance their learning process. A survey by [1] has shown that students usually formed habits and attitudes at the university during their first few days where a bad experience can critically result in either withdrawal or failure. Furthermore, [8] supported [1] by stating that such early experiences by students can easily lead to high attrition rates especially for poor experiences. Given the critical contexts, several universities worldwide including universities in SA have introduced interventions that represent the university's commitment to help these first year students cope with transitional challenges. The existing interventions focuses on individual needs and interest with the aim of bridging the gap between what 
students know and what is required by university. Accordingly, [9] and [10], orientation programme can assist students to adjust in a new environment. Nonetheless, the orientation program differs from one university to the other. In the UNIVEN context, orientation programme usually takes place a week after the registration which is also a week before lectures commences. During this period, activities that take place is captured in Fig.1.

In UNIVEN, orientation is to familiarize first year students with the important norms and practices of the university such as information about library, laboratories, student affairs office, faculties, departments and other important facilities. Moreover, HODs of each department also addresses the first year entering students and trying inform them of the discourse of the department.

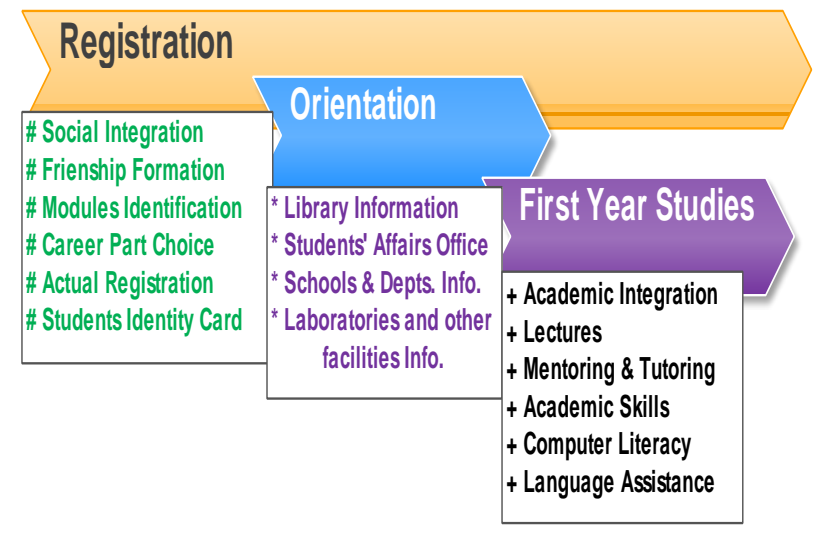

Fig.1. University opening activity model

The model in Fig. 1 is driven by the arrows. That is, students' registration first starts and continues to the middle of first year lectures while orientation is for a short period of time, perhaps, one week followed by first year lectures that spans till four months or more. In particular, the orientation programme is more of informative than supportive in nature. Thus, according to [11], establishing a supportive peer group during the first few days in the university is one valuable ways to heighten the FYE of students during their transition. Moreover, the peer groups will help them to overcome all form of difficulties encountered and boost their confidence during the first few days in the university. In the perspective of this study, our opinion is that orientation programme should be geared towards helping students of diverse backgrounds rather than just giving them information about the institution and so on. In other words, orientation period should be used to integrate students into the culture of the university, especially in the use of technologies for teaching and learning. But for it to be achieved, it is important to know what challenges students faced so that appropriate assistance can be initiated.

\section{ACCESS AND COMPUTER-BASED TECHNOLOGIES USAGE}

In this section, we present the rationale, methodology and results of the survey performed on first year entering students in UNIVEN.

\section{A. Context and Rationale}

This study assesses the use of technologies and related information of students entering the first year at the UNIVEN. To perform the investigation, important students' data were collected by creating a profile of incoming students. This is in line with the studies of [12] and [13] which reported that a profile of an incoming group is essential to be able to identify students at risk of failure, as well as those with a reasonable chance of success. Currently, this is in alignment with the researchbased approach of the University of Johannesburg (UJ) FYE in SA. In the UJ FYE, investigations were launched into the profile of the newly entering UJ students about their initial experiences and actions. Therefore, this paper adopts the same strategy of UJFYE to elicit information about our first year entering students in UNIVEN in order to enable appropriate assistance be initiated in the capacity of ICT tools usage.

\section{B. Methodology}

This study adopted a quantitative research method. Quantitative research involves the explanation of phenomena using numerical data and mathematicallybased analysis [4]. Questionnaire with semi structured questions and opinion statements was used for data collection and each was structured to elicit information about first year entering students' technology- related uses, experiences in the use of computer and its software, skill levels and training needs for the students entering the first year. There were distributed to the participants and the data collected were analyzed and reported in this paper.

\section{Study Participants}

This study focused on a specific group of students who registered for foundation programme in the school of mathematical and natural sciences at the UNIVEN. Thus, a small but significant number of participants, about 158 first year students were involved. In SA, foundation programme is an intervention by the Department of HE and Training (DHET) to promote students' successes. According to the DHET [15], HE institutions performance patterns shows that the majority of students being admitted at the universities are at risk due to poor educational backgrounds and so on. Thus, the main goal of the foundation provision is to support these students who are educationally disadvantaged or underprepared. The extended curriculum program has a duration of one year to enable the students to successfully complete their studies [16]. 


\section{RESULTS AND ANALYSIS}

The findings reported in this paper are categorized into demographic, family background, the technology-related uses, experiences in the use of computer and its software, skill levels and training needs for the students entering the first year.

\section{A. Demographic and Previous Attendance}

The participants targeted in this study were the first year students of the foundation programme. With the sample of 158 students drawn from the students' population, the analysis is shown in Fig. 2 in terms of sex and locality of previous high school attended. The results shows the students' population is dominated by female as well as students from high schools around Limpopo province in SA. In addition, their ages ranges from 15-19 years old (78\%), 20-20 years (20\%) and 25-34 years old $(2 \%)$. The indication of these results is that the first year entering students in UNIVEN are mainly dominated by learners from high schools in the Limpopo province. However, a greater number percentage of the high schools in this locality are characterized as educationally disadvantaged, under resourced and non-technological usage for teaching and learning. We believe such characteristics will have impact on their learners especially in the use of technologies. Thus, our aim is to find out the nature of these students and how they can cope with the computer-based learning system of the universities of their interest.

\section{Demographic/Previous School}

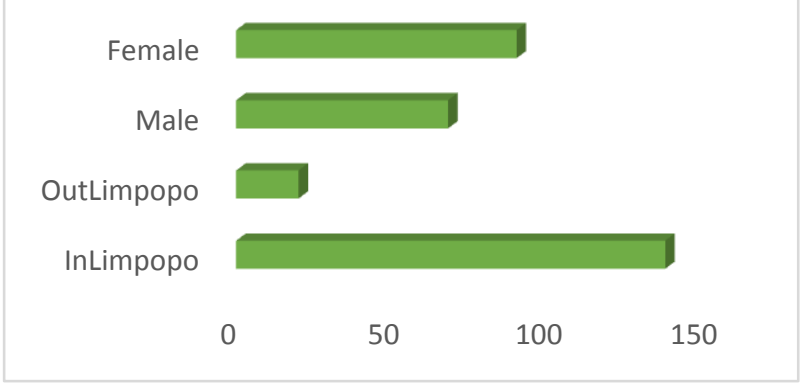

Fig.2. Previous school attended

\section{B. Family Educational Background}

In order to gain more useful information about the learners, we decided to elicit information about the participants' family educational background in terms of "Generations". The result is presented in Fig. 3 and it shows that majority of the learners were "first-generation" (FG) in their families to attend university. Firstgeneration students' in this context denotes students with parents having no university or college experience [17]. The motivation for identifying the generations of the learners is that, [18] identify FG university entrants as being at a higher than usual risk of not completing their studies. Therefore, we believed that such students are likely not to have background experiences or developed practices that are consistent with the way things are or done at the university. Also, such students will have no access to close family members who could provide them with the appropriate academic, social supports and guidance.

\section{First Generation Students}

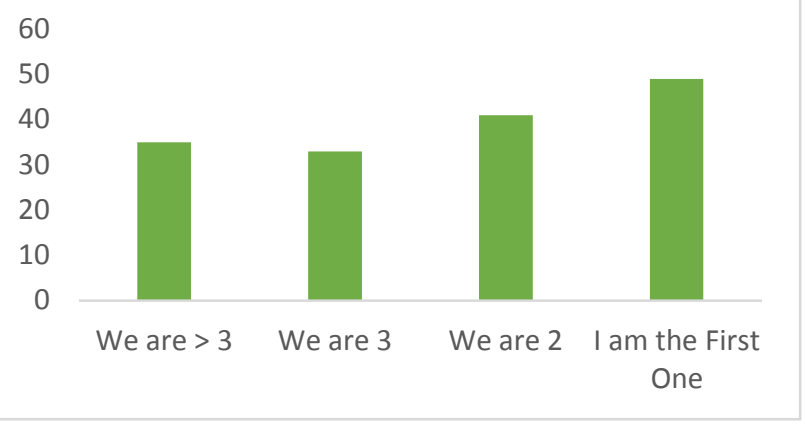

Fig.3. Family educational background

Moreover, [19] reported that "the gap between previous life experiences and the challenges posed by HE is deeper and wider" for these students than for traditional university entrants. Thus, the identification of such students is to enable the institution provide the required support they need to excel in their educational pursuit.

\section{Computer and Mobile Phones' Ownership}

Based on the findings of the students' educational and family backgrounds, we proceed further to identify which technologies the first year students have or have used. This is captured in Fig. 4 showing both computer and mobile phones' ownerships in the students' family.

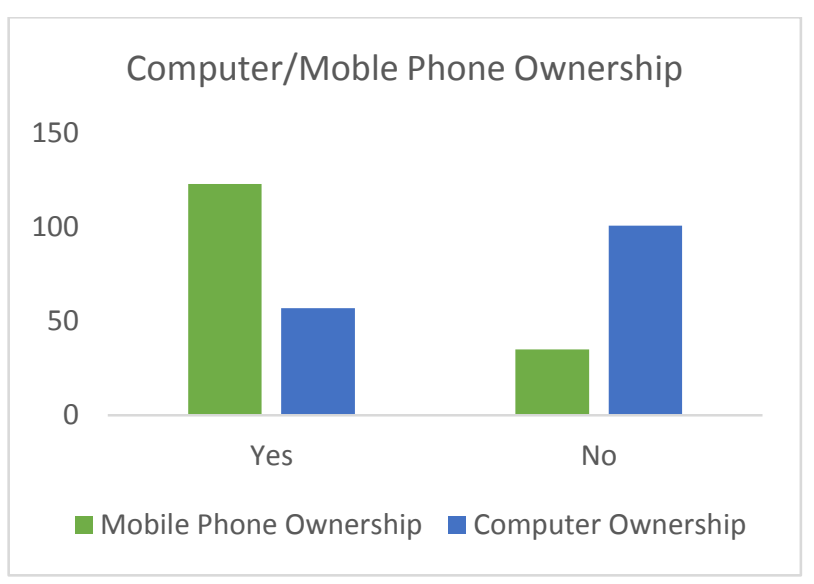

Fig.4. Computer and mobile phone ownership

The essence of identifying which technologies were owned by the students' family was to gain information about the impact of family's background on the students in terms of technology usage or ownership. The intuition is that a family where technologies are not used or owned would likely manifest in the learner's inability to use or own one. As captured in Fig. 4, a greater proportion of the students' family did not own a computer but majority 
own at least a mobile phone in their family for communication. However, this study did not investigate whether the phone is smart or not and can access the Internet or not.

\section{Technology Usage and Skills in the Context of Teaching and Learning}

There has been debates going on in the literature about the claims made about 'digital natives' or the 'net generation' [20] and [21] respectively and their abilities to use technologies as well as the need to modify curriculum design and delivery [22] to reflect their skills and expectations. In order to identify the strengths and weaknesses of the students in the use of technology for teaching and learning, students were asked about their previous information technology (IT) training, use of computer hardware and software applications for teaching and learning. The results of the analysis is shown in Fig. 5. The goal is to enable the institution provides students' profile on computer technologies in terms of experience, their expectations of doing the course called Foundation IT (FIT), their knowledge in the use of application software (such as Ms-Word, Ms-Excel, etc.), and the technologies they would like to use for their studies in order to provide the appropriate support to integrate the students into their computer-based culture of teaching and learning.

\section{Technology Usage and Skills for Teaching/Learning}

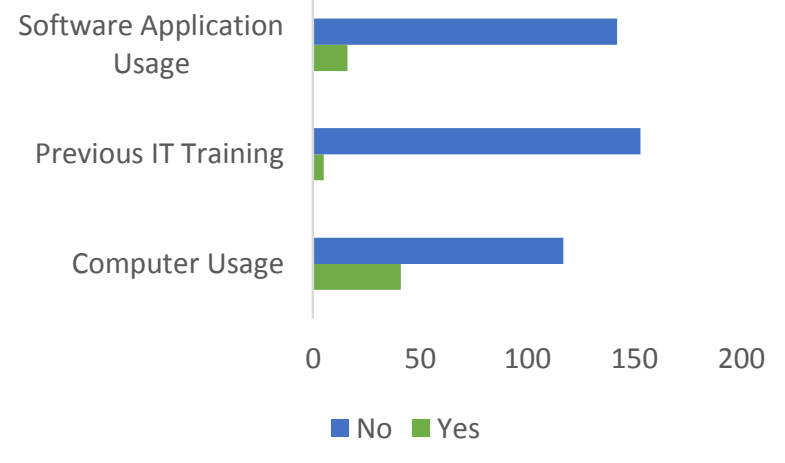

Fig.5. Teaching and learning technology usage

As presented in Fig. 5, analysis indicates that almost all the students did not received IT training prior to their university admission and only few have used computers, $26 \%$ in the context of teaching and learning. This can be attributed to the nature of high schools the students attended as dominated in the Limpopo rural areas. In addition, a greater proportion of the students' population indicated they have not used software applications like MS Word, Excel, PowerPoint and so on to perform class assignments, essay or laboratory reports. For those that have used software applications, when further asked to describe their skills in the use of basic software applications they will be encountering on daily basis during the course of teaching and learning, the results is shown Fig. 6.

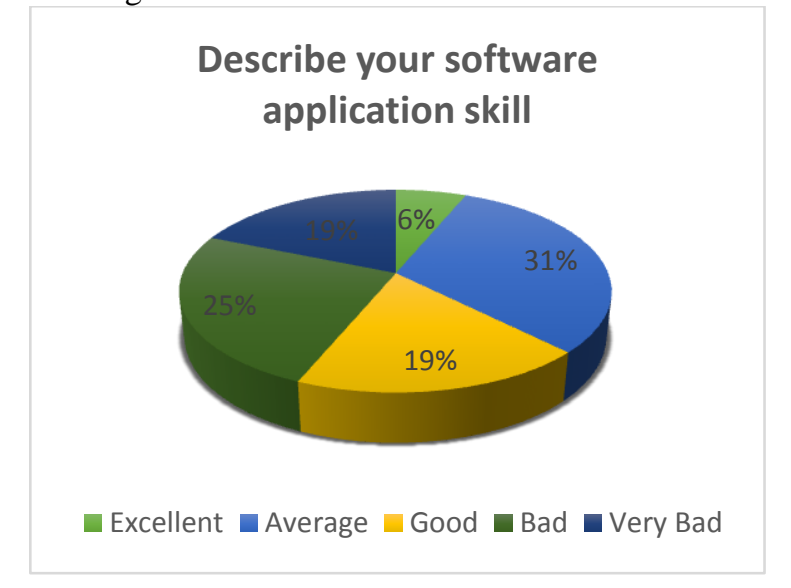

Fig.6. Software application knowledge

As shown in Fig. 5 and 6, analysis of the trends in technology usage and skills revealed a considerable percentages of non-use of computer-based technologies by the first year entering students. Reasons could either be as a result of the age group of the students or the nature of the high school attended or even family background.

\section{E. Technology Adoption}

Given the above participants' responses on the use of technologies, this section is designed to offer assistance to students where challenges have been identified in terms of teaching and learning. Consequently, when asked if they need training on basic technologies to be used in teaching and learning, the results indicates almost every students (95\%) showed interest on basic IT training in terms of hardware and software to help them carry out their studies effectively. In terms of the nature of training, majority of the first year students indicated they need all forms of IT and computer usage training while about 12 students needed only training in e-learning and 8 students showed interest in typing training. (See Fig. 7)

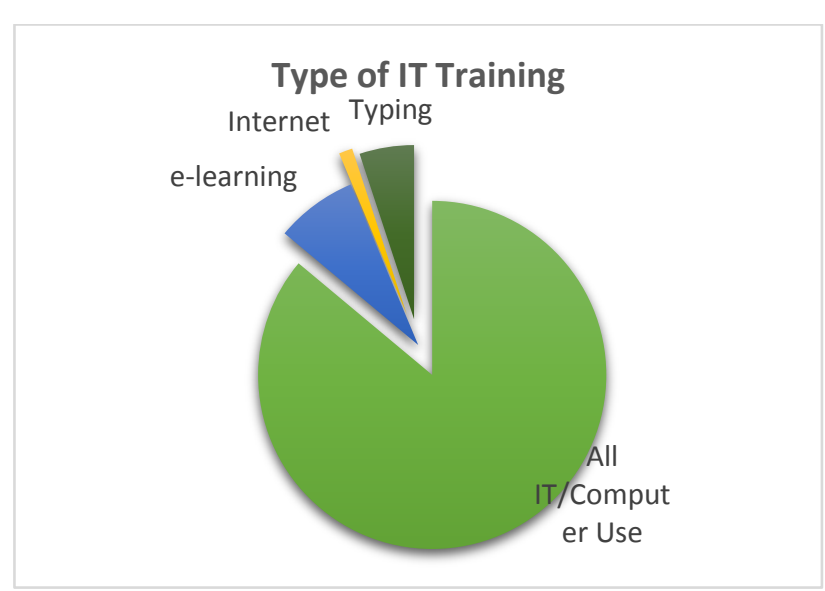

Fig.7. Types of training needs 


\section{DISCUSSIONS}

In HE today, the impact of the ICTs in teaching and learning has been valuable and highly commended. However, in order to accommodate students with diverse backgrounds and meet their dynamic needs, they have to be provided with the required and valuable supports in order to help them cope with the use of technologies in their learning process. To this end, this study carried out a survey to elicit information about first year students at UNIVEN during students' first year registration which will be used during the orientation period to provide the necessary assistance to cope with the teaching and learning activities.

Based on the analysis performed and results obtain as presented in Fig. 2 to 7 , it shows that a greater proportion of the students were from several high schools in the Limpopo locality which are characterized as underresourced or educationally disadvantaged. Also, high proportion of the students are the first persons to attend universities in their families. Consequently, we believed being FG could likely have negative impact on the students especially as there is no one to guide them academically. Furthermore, in terms of technology ownership, majority of the students showed their families have not own a computer $(64 \%)$ while almost every household owned mobile phones (78\%). In the perspective of technologies usage for teaching and learning activities, the responses from the students (97\%) showed that they have not been trained or had IT knowledge of any kind. More so, a greater proportion of the first year students (74\%) responded they have not used computer for teaching and learning activities while about $50 \%$ indicated they have no knowledge of software applications such as MS Word, etc. also, about $90 \%$ indicated they have not used any of the software or other IT tools to perform academic tasks like assignments submission, reports, essay and so on.

With the results obtained from this survey, we believe they reflects the nature of the high school attended or the previous knowledge the students have been exposed to. Moreover, this study have provided enough justification to provide supports to such learners characterized as under-pared. This is because UNIVEN will likely continue to experience serious challenge to get these students cope with the technologies for teaching and learning if appropriate actions are not setup. To this end, about $95 \%$ of the students indicted interest in computer literacy training in order to get them integrated into the university technology-based system. This therefore, calls for FYE computer literacy module to be introduced to help deal with the complex challenges first year students will face in their learning process during orientation.

\section{PROPOSED FIRST EXPERIENCE COMPUTER LITERACY MODULE}

There has been a significant change over the last century with the rapid growth in IT and their associated tools in education. Based on the analysis performed on first year students' profile, it shows that first entering students have had very little access to or no access to computers prior to their university education. Thus, our position in this paper is that a FECOL module should be implemented to assist students cope with different technologies in their learning process. In particular, FECOL will have the capacity to equip students with basic knowledge and technological skills that they need in terms of computer literacy. By computer literacy, we mean the knowledge and ability to use computers and associated technologies efficiently in the context of teaching and learning. Therefore, at the first year students' level, the proposed FECOL module will consist of three main components: (1) introduction to computer, (2) introduction to application software and, (3) introduction to technological tools for teaching and learning. (See Fig. 8). In the context of UNIVEN, the stated course contents is derived by combining the components of a basic computer literacy (COM 0510) and Foundation Information Technology (FIT) course and an introduction to technological tools that is used for research, teaching and learning as well as the campus intranet.

Introduction to Computer: This is the first component and is designed to assist the new student familiarize with the computer system such as hardware, software, user, commands, security so on (See Fig.8). This is necessary to allow students to learn how to operate computer device as well as develop knowledge and skills that include understanding basic concepts as well as the ability to perform basic tasks.

Introduction to Application Software: This component is designed to assist new student to get use with a various number of productivity software and the user interfaces that will help them to perform specific tasks such as typing, searching information on the Internet, printing, effective communication and collaborations with other students and the teachers.

Introduction to Technological Tools for Teaching and Learning: As one of UNIVEN strategic plan initiatives for 2009-2015 [23], the institution implemented elearning and distributed PC tablets to the students to be use as an innovative tools for teaching and learning. Thus, this component will introduce new students to the use of various technological tools that are used at the university such as library databases, Turnitin and other plagiarism software, referencing, e-learning, Pc-tablet use and so on.

Given the FECOL components highlighted above, the module intention is to provide all new students with basic skills and understandings required for them to become an emergent user and computer literate especially in the capacity of performing specific task at the beginning of their studies. The idea is also to allow students to become technological relevant to the university online learning environment and also depend on the use of computer technology in their teaching and learning activities. We believe that if this module is implement as part of students' orientation activities, it will go a long way to assist them to integrate and achieve their learning outcome hitch-free. 


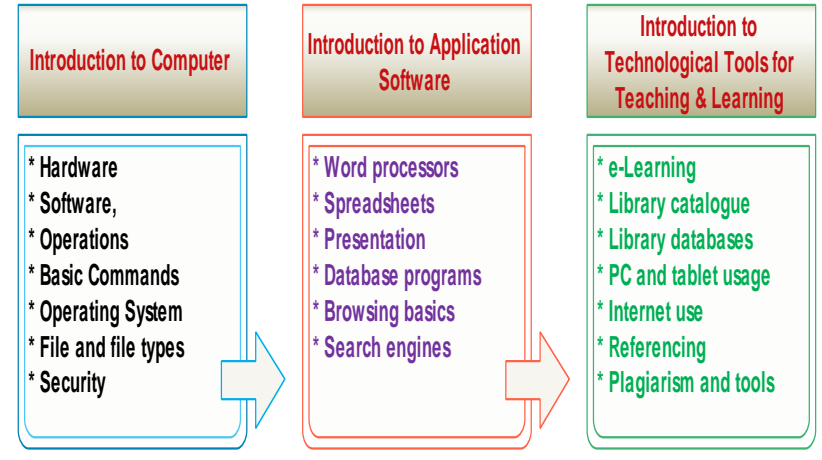

Fig.8. FECOL module components

\section{CONCLUSION}

This paper presents the assessment performed on first year students in terms of the use of technologies and other relevant information. The assessment was performed to identify challenges students with diverse backgrounds will face in their learning process with recommended teaching and learning technologies. The study performed a survey on first year students at UNIVEN and profile information were collected. Analysis was performed and the results obtained shows the first year students at the institution were mainly from Limpopo region, majority were first of the kind to attend university in their family as well, have not had technological training or used them in course of teaching and learning. Moreover, majority of the first entering students indicated they need some forms of computer training in order to assist them cope with the technologybased learning system. Furthermore, based on the students' responses from the survey as well as experience academics had with these students, this study proposed a FECOL module to be implemented during orientation programme in the institution to help students with to acquire basic technologies skills they need to integrate into the university system. We therefore conclude that, if FECOL module is implemented instead of informative orientation during the first few days of opening in the university, it could go a long way to positively impact both the institution and students in their teaching and learning process.

\section{REFERENCES}

[1] C. McInnis, R. James, and C. McNaught. First year on campus: diversity in the initial experiences of Australian undergraduates. Canberra: Australian Government Publishing Service, 1995

[2] M. Peel, "Studying the Transition from year 12 to the first year of Higher Education", Proceedings of the 2nd Pacific Rim Conference on the first year in Higher Education, Melbourne: Centre for the Study of Higher Education, 1996
[3] B. Jones, G. Coetzee, T. Bailey and S. Wickham, "Factors that facilitate success for disadvantaged students: An investigation into approaches used by REAP, NSFAS and selected higher education institutions", Cape Town: REAP, 2008

[4] M. Prensky, "Digital Natives, Digital Immigrants: Part 1". On the Horizon, 9(5), 1-6, 2001

[5] University of Mentoring Guidelines, 2011

[6] Murphy, Liam, and Thomas Nagel, "Taxes, Redistribution, and Public Provision." Philosophy and Public Affairs 30 (1): 53-71, 2001.

[7] V. Tinto, "Dropout from Higher Education: A Theoretical Synthesis of Recent Research" Review of Educational Research vol.45, pp.89-125, 1975

[8] V. Tinto, "Leaving College", Chicago, University of Chicago Press), 1987

[9] S. Donnison \& S. Penn-Edwards, Reflecting on the first year experience in higher education through metaphoric language. Manuscript in preparation, 2012

[10] L. Harvey, S. Drew, \& M. Smith, "The first-year experience: A review of literature for the Higher Education Academy". York, UK: The Higher Education Academy, 2006

[11] C. McInnis, \& R. James, with C. McNaught, "First year on campus: Diversity in the initial experiences of Australian undergraduates". Canberra: AGPS, 1995

[12] J.R Keup, "The First year Experience: Lessons learned and emerging issues". Presentation to the First Year Success conference held at the University of Johannesburg 17 September 2013. Unpublished slides

[13] M.L Laskey, \& C.J Hatzel, "Investigating Facors Realted to Retention of At-risk College Students". The Learning Assistance Review (TLAR), 16 (1): 31-43, 2011

[14] M. Aliaga, \& B. Gunderson, "Interactive Statistics". Saddle River, p3-15, 2000

[15] Department of higher education and training (2012), Annual report: 2012

[16] M. Mbodila, C. Ndebele, and M. Kikunga, "The Effect of Social Media on Student's Engagement and Collaboration in Higher Education: A Case Study of the Use of Facebook at a South African University". Journal of communications 5.20, pp.115-125, 2014

[17] Lowe-McConnell, R.H., "Cichlids all! With an ecological view of African cichlids". Environ. Biol. Fish. 63(4):459463, 2002.

[18] N. Falchikov,"Learning together: peer tutoring in higher education" (London, RoutledgeFalmer), 2001

[19] M. Vosloo, \& S. Blignaut, "From hero to zero ... and back? The journey of first year ccess students in mainstream programmes". ASSAF "Mind the Gap" forum, October 2010

[20] G. Conole, M. de Laat, T. Dillon, \& J. Darby, "LXP: Student experience of technologies". Final report. JISC, UK, 2006.

[21] K. Trinder, J. Guiller, A. Margaryan, A. Littlejohn, \& D. Nicol. "Learning from digital natives: Integrating formal and informal learning". The Higher Education Academy, UK, 2008

[22] D. Boud, R. Cohen, \& J. Sampson, "Peer learning in higher education: learning from and with each other" (London, Kogan Page), 2001

[23] University of Venda strategic plan initiatives for 20092015, 2009. 


\section{Authors' Profiles}

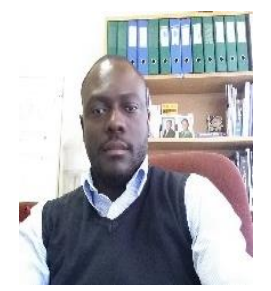

Munienge Mbodila holds B.Sc. (Hons) degree in Computer Science at the University of Fort Hare, 2013 and M.Sc. degree in Computer Science in 2014 at the North-West University, South Africa and PG Diploma in Higher Education in Teaching and Learning in 2015 at Stellenbosch University, South Africa. He joined the Department of Computer Science and Information System of the University of Venda as a faculty member and as a Lecturer in 2009. His research interests include Computer Networks, Wireless Sensor Networks, Software Engineering, ICTs and Web Technology in Teaching and Learning.

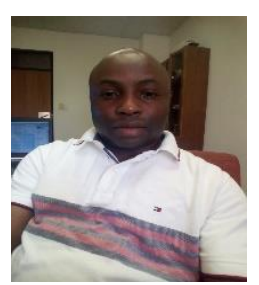

Isong Bassey received B.Sc. degree in Computer Science from the University of Calabar, Nigeria in 2004 and M.Sc. degrees in Computer Science and Software Engineering from Blekinge Institute of Technology, Sweden in 2008 and 2010 respectively. Moreover, he received a $\mathrm{PhD}$ in Computer Science in the North-West University, Mafikeng Campus, South Africa in 2014. Currently, he is a Lecturer in the Department of Computer Sciences, Mafikeng Campus, North-West University. He is also a member of IEEE, IEEE Computer Society and Education Society. His research interests include Software Engineering, Requirements Engineering, Software Maintenance, Cybersecurity, Software-Defined Networks, Cloud and Mobile Computing, ICT4D and Computer Science Education.

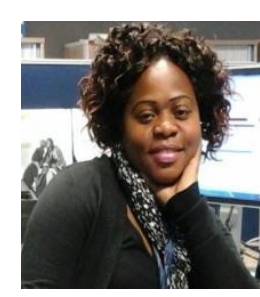

Muhandji Kikunga holds B.Sc. (Hons) degree in Computer Science at the University of Fort Hare in 2013 and M.Sc. degree in Computer Science in 2014 at the North-West University, South Africa. She is currently a faculty member in the Department of Computer Science and Information Systems at the University of Venda, South Africa. Her research interests include: e-Health, e-Learning, ICT in Teaching and Learning, Networks, Cloud Computing and Information Systems Security.

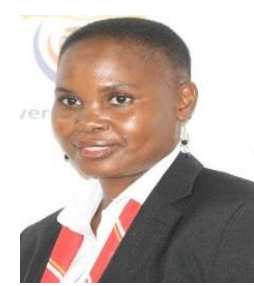

Langutani Masehela holds a $\mathrm{PhD}$ in higher education studies from Rhodes University, South Africa. She is a senior educational development practitioner, student support at the University of Venda's Centre for Higher Education Teaching and Learning in the Academic Development Unit. Her main responsibilities are to facilitate the implementation of student support programmes such as mentoring and tutoring as well as responsible for conducting workshop courses on academic literacies to mainly first year students. Her research interests are issues around the quality of teaching and learning in higher education, student academic support (student peer mentoring and tutoring), first year experience and academic staff development issues.

How to cite this paper: Munienge Mbodila, Isong Bassey, Muhandji Kikunga, Langutani Masehele,"On Overcoming Transitional Challenges of First Year Students in Technology-Based Educational Settings", International Journal of Modern Education and Computer Science(IJMECS), Vol.8, No.11, pp.28-35, 2016.DOI: 10.5815/ijmecs.2016.11.04 